\title{
S-Adenosyl-Methionine Decarboxylase Inhibitor
}

National Cancer Institute

\section{Source}

National Cancer Institute. S-Adenosyl-Methionine Decarboxylase Inhibitor. NCI

Thesaurus. Code C2090.

Any substance that inhibits S-adenosyl-methionine decarboxylase, an enzyme involved in the biosynthesis of the polyamines spermidine and spermine. Polyamines are essential for cell division, cell differentiation and membrane function and inhibition of S-adenosylmethionine decarboxylase results in inhibition of cell growth and differentiation. 